\title{
Omega-3 and Vitamin E Supplementation Effect to Rattus Norvegicus Placental Apoptosis Marker: Pre-Eclampsia Model
}

\author{
Yesi Gusti ${ }^{1}$, Arni Amir ${ }^{1,2}$, Gusti Revilla ${ }^{1,2}$ \\ ${ }^{1}$ Midwifery Magister Program, Medical Faculty, Andalas University, Jl. Perintis Kemerdekaan No.94 Padang, \\ Indonesia, 25127 \\ ${ }^{2}$ Departement of Biology, Medical Faculty, Andalas University, Kampus Universitas Andalas Limau Manis, \\ Indonesia, 25163 \\ Corresponding Author: Yesi Gusti
}

\begin{abstract}
Background: Pre-eclampsia has been associated with the increased of placental apoptosis caused by oxidative stress. Omega-3 fatty acids and vitamin $\mathrm{E}$ had beneficial function to maintain cell membranes, prevent oxidative stress and inhibit the production of proinflammatory cytokines. The purpose of the study was to determine the effect of omega-3 and vitamin E supplement to BCL-2 and BAX on PE rats model.

Methods: This research has been worked out at animal house and Biomedical Laboratory of the Medical Faculty Andalas University. The design of this research was experimental study with post test only control group design. There were 35 pregnant rats were divided into 5 groups. Group K- without treatment, group $\mathrm{K}+$ was given L-NAME, group P1 was given L-NAME + omega-3, group P2 was given L-NAME + vitamin $\mathrm{E}$ and group $\mathrm{P} 3$ was given L-NAME + omega-3 + vitamin E. The L-NAME dose was $50 \mathrm{mg} / \mathrm{kg} /$ day, At the $19^{\text {th }}$ day of gestation, the pregnancy was terminated and the placental tissue was collected for examining BCL-2 and BAX levels by using ELISA kit. The data were analyzed by one way ANOVA and post hoc test LSD.
\end{abstract}

Results: The mean levels of BCL-2 in each group were $\mathrm{K}-=62.49 \mathrm{ng} / \mathrm{mg}, \mathrm{K}+=50.64$ $\mathrm{ng} / \mathrm{mg}, \mathrm{P} 1=58.79 \mathrm{ng} / \mathrm{mg}, \mathrm{P} 2=53.70 \mathrm{ng} / \mathrm{mg}$ and P3 $=70.10 \mathrm{ng} / \mathrm{mg}$. The mean levels of BAX were $\mathrm{K}-=72.06 \mathrm{ng} / \mathrm{mg}, \mathrm{K}+=78.61 \mathrm{ng} / \mathrm{mg}, \mathrm{P} 1$ $=73.71 \mathrm{ng} / \mathrm{mg}, \mathrm{P} 2=74.31 \mathrm{ng} / \mathrm{mg}$ and $\mathrm{P} 3=71.63$ $\mathrm{ng} / \mathrm{mg}$. The analysis results concluded that there were significant differences between omega-3 and vitamin E supplements on BCL-2 levels $(\mathrm{p}=0.000)$ and BAX levels $(\mathrm{p}=0.001)$.

Conclusion: Omega-3 (DHA 120 mg, EPA 180 $\mathrm{mg}$ ) and vitamin E ( $\alpha$-tocopherol $300 \mathrm{iu}$ ) suplement increased BCL-2 level and decreased BAX on pre-eclampsia rats model.

Keywords: Omega-3, Vitamin E, BCL-2, BAX, Pre-eclampsia

\section{INTRODUCTION}

Pre-eclampsia (PE) is a major complication in pregnancy and a major cause of maternal and perinatal mortality and morbidity. It was estimated that 50,000 - 60,000 maternal mortalilty caused by preeclampsia per year. World Health Organization (WHO) estimated that preeclampsia rate were seven times higher in developing countries than developed countries. Pre-eclampsia prevalence in developed countries was $1.3 \%$ - $6 \%$, while in developing countries three time higher $(1.8 \%$ - 18\%). The incidence of preeclampsia in Indonesia was 128,273 /year or about $5.3 \%$ of the pregnancies (1). PE define as pregnancy syndrome that causing damage to multiorgan and diagnosed after $20^{\text {th }}$ week of gestation. Clinical signs and symptoms of PE include increase or high blood pressure, protein urea, swelling, headache, visual disturbance and sudden weight gain (2). Pre-eclampsia is also 
Yesi Gusti et.al. Omega-3 and vitamin E supplementation effect to rattus norvegicus placental apoptosis marker: pre-eclampsia model.

associated with poor fetal condition, including; fetal growth retardation, placental abruption, oligohydramnios and fetal death. Complications that can arise associated with $\mathrm{PE}$ are disseminated intravascular coagulation (DIC), cerebral hemorrhage, acute renal failure, liver damage, pulmonary edema, blindness, and seizures. PE is also closely related to cardiovascular diseases that can arise later in life such as hypertension, stroke, ischemic heart disease, and so on. The earlier the symptoms appear, the less the diagnosis is pure pre-eclampsia and have higher chance that the disease will persist into hypertension after delivery (2)(3).

Pre-eclampsia results from impaired trophoblast differentiation and invasion in early pregnancy resulting in the failure of trophoblast cells to destroy the muscularis layer of the spiral arterioles resulting in the development of a poorly perfused placenta and stimulation of a systemic inflammatory response. However, this reduced placental perfusion alone is not sufficient to cause the maternal syndrome of pre-eclampsia and it is thought that this process requires the influence of additional maternal factors including genetic make-up and environmental factors (such as obesity and diet), which together results in widespread endothelial dysfunction and hypertension (4). Placental ischemia and hypoxia produce highly toxic hydroxyl radicals. These hydroxyl radicals damage endothelial cell membranes which are rich of unsaturated fatty acids, converting them into lipid peroxides that the final product is malondialdehyde (MDA). The increase of MDA with hypoxia indicates oxidative stress (5) (6).

Oxidative damage in the placenta caused by impaired remodeling of the spiraled uterine arteries leads to inflammation, apoptosis and the release of cellular debris into maternal circulation along with several anti-angiogenic factors, such as soluble fms-like tyrosine kinase-1 (sFlt1) and soluble Endoglin (sEng), cytokines and oxidants. These placental- derived factors act on the maternal vascular endothelium, inducing oxidative stress and stimulating the production and secretion of pro-inflammatory cytokines, as well as vasoactive compounds (7). Oxidative stress also can induce apoptosis via extrinsic or intrinsic signals. The former are mediated by cell-surface death receptor Fas-induced caspase-8, while the latter are transmitted by mitochondria-mediated caspase- 9 pathways. The two signaling pathways do not completely separate as they converge on the activation of caspase-3, resulting in apoptotic like chromatin condensation and cell shrinkage. Oxidative stress could also modify some key apoptotic regulators, such as proteins of the $\mathrm{Bcl}-2$ family, p53, and components like apoptosis signal-regulating kinase-1 (ASK-1), c-JNK, and p38 MAPK (8).

The regulation of the apoptotic process varies. BCL-2 as an antiapoptotic agent will block cell death programs and maintain cell life. The increase of BCL-2 protects lymphocytes from apoptosis and allows these cells to survive for a long period. BCL-2 also has another function as an antioxidant to protect cells. The increase of BCL-2 Associated X protein (BAX) is always inversely proportional to BCL-2, which works to accelerate cell death. Antiand proapoptotic ratios of BCL-2 family proteins determine the reaction to various apoptotic stimuli. The balance of BCL-2 and BAX also plays an important role in maintaining the balance of cell survival (9)(10).

Vitamin E, especially $\alpha$-tocopherol has the main function as an antioxidant, thus acting as a chain breaking antioxidant that will capture peroxyl radicals and provide phenolic hydrogen. Then, result less reactive products and stop the lipid peroxidation cycle (11). In a study to women who receive oral vitamin $C$ in dose $500 \mathrm{mg}$ and oral vitamin $\mathrm{E}$ in dose of 400 IU per day, there was a $46 \%$ risk reduction in the incidence of preeclampsia in cases as compared to controls. The incidence of severe preeclampsia in cases was $2 \%$ and in 
Yesi Gusti et.al. Omega-3 and vitamin E supplementation effect to rattus norvegicus placental apoptosis marker: pre-eclampsia model.

controls was $7 \%$. This result showed $72 \%$ reduced risk in the development of severe preeclampsia in cases as compared to controls (12).

Omega-3 PUFAs supplementation during pregnancy has shown improve pregnancy quality and reduce pregnancy complications risk, although the exact mechanism that regulates this effect remains uncertain. Omega-3 PUFAs are involved in several physiological processes through anti-oxidative, anti-inflammatory and proresolving pathways (13). There is a relationship between omega-3 fatty acids and apoptotic markers in the placenta of pregnant women. Women who were supplemented with docosahexaenoic acid (DHA) during pregnancy, reported, has lower placental caspase-3 levels compared to women who were not given the supplement (14).

\section{METHOD}

\section{Design and sampling}

This research was an experimental study, specifically post test only control group design. That comparing the experimental group with the control group. The sample that used for the treatment were Rattus Norvegicus wistar strain. There were 35 pregnant rats were divided into 5 groups. The normal pregnant rats group without treatment (K-) as the negative control, the group given L-NAME $(\mathrm{K}+)$ as positive control, the group given L-NAME + omega3 (P1), the group given L-NAME + vitamin $\mathrm{E}(\mathrm{P} 2)$ and the group given L- NAME + omega-3 + vitamin E (P3). This research has passed out an ethical clearence from the Ethics Committee of Medical Faculty, Andalas University with certificate No: 344/UN.16.2/KEP-FK/2021.

\section{Treatment dose}

L-NAME was used to create hypertensive state on pregnant rats like preeclampsia, given orally on the $10^{\text {th }}$ to $19^{\text {th }}$ day of gestation. The dose of L-NAME administration was $50 \mathrm{mg} / \mathrm{kg} /$ day. Omega-3 (180 $\mathrm{mg}$ EPA and $120 \mathrm{mg}$ DHA) that we used were Omeheart $300 \mathrm{mg}$ from Mywell and vitamin E 300 iu from Sidomuncul that equivalent to $300 \mathrm{mg} \alpha$-tocopherol.

\section{Placental collection}

At the $19^{\text {th }}$ day of gestation, the pregnancy was terminated and the placental tissues were collected. The Placental tissues washed out with phosphate buffered saline (PBS) solution (0.02 mol, $\mathrm{Ph}$ 7.0-7.2) from remaining blood. The tissues were grinded out into small pieces and homogenized in PBS with a cold-temperature homogenizing glass. Amount $1.0 \mathrm{mg}$ placental tissue homogenized with $9 \mu$ PBS solution (0.01 $\mathrm{M}, \mathrm{Ph}=7.4)$. The suspension used for ultrasonication or two freeze-thaw cycles to break up the cell membrane. The suspension was centrifuged at $5000 \mathrm{x}$ g for 5 minutes. Supernatants samples cell derived from placental trophoblasts stored at $-20{ }^{0} \mathrm{C}$ before next step.

\section{BCL-2 and BAX examination}

All samples were examined by ELISA using Rat Apoptosis Bcl 2 Elisa Kit from BT-LAB catalog no E0037Ra for BCL-2 examination and using Rat Apoptosis Bcl 2-Associated X Protein Elisa Kit from BT-LAB catalog no E0034Ra for BAX. Each sample was made in duplicate to ensure the result better.

\section{Data analyze}

The data were analyzed by Shapirowilk, the result got was normal for normality test. Because the data got normally distributed ( $\mathrm{p}$-value $=0,252$ for BCL-2 and 0,743 for BAX), so we proceed to one-way ANOVA analysis with $95 \%$ confidence degree $(\alpha=0.05)$. Then analysis was continued with the LSD post hoc test.

\section{RESULT \\ BCL-2 Levels}

The mean levels of BCL-2 in the normal pregnant rats group (K-) was different from the group of pre-eclampsia model rats $(\mathrm{K}+)$. The mean level of the placental BCL-2 for normal pregnant rat 
Yesi Gusti et.al. Omega-3 and vitamin E supplementation effect to rattus norvegicus placental apoptosis marker: pre-eclampsia model.

(K-) was $62.49 \mathrm{ng} / \mathrm{mg}$, while in $\mathrm{K}+$ was $50.64 \mathrm{ng} / \mathrm{mg}$. This shows that L-NAME administration makes the BCL-2 level of the rat placenta lower.

Table 1 BCL-2 mean levels on each group based on treatment

\begin{tabular}{|l|l|l|l|}
\hline Groups & $\begin{array}{l}\text { Mean } \\
\text { (ng/mg) }\end{array}$ & Std. Deviation & p-value \\
\hline K - & 62,4933 & 5,49184 & \multirow{2}{*}{0,000} \\
\hline K + & 50,6417 & 5,35165 & \\
\hline P1 & 58,7950 & 5,10243 & \\
\hline P2 & 53,7017 & 3,49636 & \\
\hline P3 & 70,1050 & 3,26164 & \\
\hline Total & 59,1473 & 8,17659 & \\
\cline { 1 - 2 } & & & \\
\end{tabular}

The K+ group had the lowest BCL-2 mean level among the other groups, which was $50.64 \mathrm{ng} / \mathrm{ml}$. The group of preeclampsia model mice that were given omega-3 (P1) appeared to have BCL-2 mean level was closed to the normal pregnancy group, while the P2 had BCL-2 mean levels not so different from the preeclampsia group $(\mathrm{K}+)$. The group that treatment with combination of omega- 3 and vitamin $\mathrm{E}$ appeared to have the highest placental BCL-2 mean levels among the other groups (Table 1).

The results of the analysis of mean differences levels of BCL-2 placentas of pregnant rats in the treatment group and the control group obtained $\mathrm{p}$ value $=0.000(\mathrm{p}<$ 0.05 ). It can be concluded that there is a significant difference in BCL-2 levels of rat placenta between the treatment and control group.

\section{BAX Levels}

The mean level of placental BAX on normal pregnant rats was $72.06 \mathrm{ng} / \mathrm{mg}$. The group that had the highest BAX mean level among the other groups was $\mathrm{K}+$ group. This proves that the administration of LNAME has an effect on the high levels of BAX in the rat placenta.

Table 2 BAX mean levels on each group based on treatment

\begin{tabular}{|l|l|l|l|}
\hline Groups & $\begin{array}{l}\text { Mean } \\
\text { (ng/mg) }\end{array}$ & Std. Deviation & p-value \\
\hline K - & 72,0583 & 4,08301 & \multirow{2}{*}{0,001} \\
\hline K + & 78,6067 & 3,05425 & \\
\hline P1 & 73,7117 & 1,78094 & \\
\hline P2 & 74,3150 & 2,27272 & \\
\hline P3 & 71,6300 & 1,68453 & \\
\hline
\end{tabular}

The group of pre-eclampsia rats model that were given combination of omega-3 and vitamin E appeared to have the lowest mean BAX levels. Furthermore, the group of pre-eclampsia rat model that supplemented by omega-3 also had placental BAX mean levels that was almost close to the normal pregnant group (Table 2).

The one-way ANOVA analysis of the means difference on placental BAX levels obtained $\mathrm{p}$ value $=0.001$. This result shown that at $5 \%$ alpha, it can be concluded that there was a significant difference between placental BAX levels between treatment and control group.

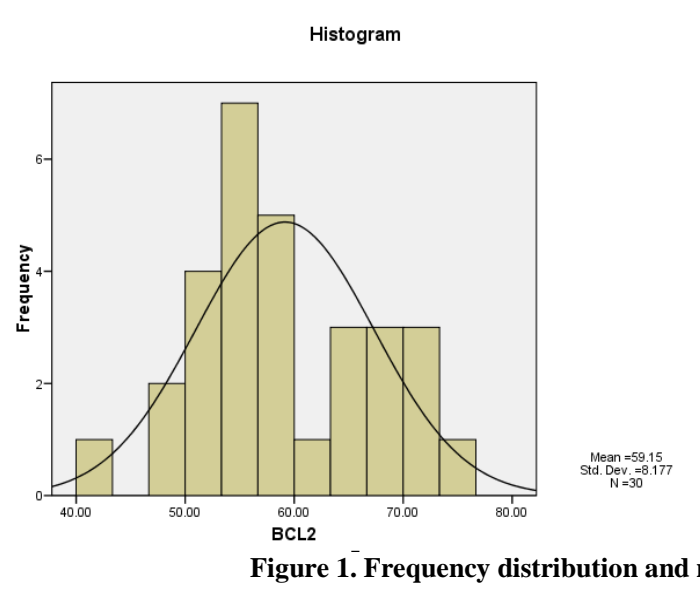

\section{DISCUSSION}

Programmed cell death (apoptosis) plays an important role during the development of the placenta and in the

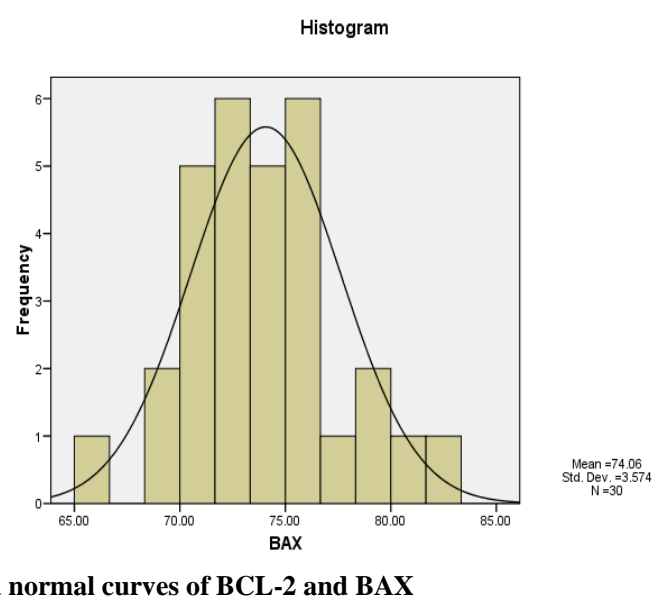

regulation of its ageing during pregnancy. The regulation of programmed cell death is complex; both proapoptotic (stimulating programmed cell death) and antiapoptotic 
Yesi Gusti et.al. Omega-3 and vitamin E supplementation effect to rattus norvegicus placental apoptosis marker: pre-eclampsia model.

(inhibiting programmed cell death) genes are involved. Members of the Bcl-2 (B cell lymphoma 2) protein family play a prominent role in this complex regulatory system (15). The B-cell lymphoma/leukemia (Bcl-2) is an antiapoptotic protein that regulates apoptosis by preventing cell death. PE is often accompanied by hypoxia of the placenta, and this condition induces apoptosis in trophoblastic cells. Hypoxiainduced apoptosis accompanied by decreased BCL-2 expression (16) BCL-2 from antiapoptotic group, and BAX from proapoptotic group had the strongest biological effects. BCL-2 is located on the outer mitochondrial membrane and inhibits the action of pro-apoptotic proteins such as BAX (16)(17).

The increased of BAX expression while the absence or decrease BCL-2 triggers an apoptotic cascade reaction. The cascade is initiated by the release of mitochondrial cytochrome-c into the cytosol and interacts with Apaf-1 to form an apoptosome that binds and activates procaspase-9. Activation of caspase-9 cleaves its effectors; caspase-3, caspase-6 and caspase-7. Effector caspases then cleave many substrates in cells and lead to characteristic morphological changes in apoptosis (18).

In this study, the BCL-2 mean level in pre-eclampsia rats model was lower or significantly different from normal pregnant rats. Omega-3 supplements (p-value = 0.005 ) and the combination of omega- 3 and vitamin $\mathrm{E}$ (p-value $=0.000$ ) were associated with higher levels of BCL-2 placentas in pre-eclamptic rat models compared to the control group. While the administration of vitamin $\mathrm{E}$ only, had no effect (p-value = 0.264). Omega-3 and vitamin E supplementation only, or in combination, had the same effect on rat placental BAX levels.

Omega-3 PUFAs has the potential effect to inhibit oxidative stress by increasing ROS binding capacity and limiting ROS regeneration. Omega-3 supplementation also increase mRNA expression and activity of major antioxidant enzymes in the placenta and reduced placental oxidative damage (13). Cardiolipin (CL) is a unique phospholipid found in the inner mitochondrial membrane (IMM), where CL associated with several enzymes required for oxidative phosphorylation, including cytochrome c. Since mitochondria is the main source of intracellular ROS, especially in complexes I and III, CL directly affected by relatively high ROS concentrations in mitochondrial stress. In addition, CL also contains four unsaturated fatty acyl chains, making it more susceptible to oxidation. CL-bound cytochrome c also serves as a cardiolipinspecific peroxidase that can oxidize CL in an H2O2-dependent manner. After oxidation, CL dissociates from enzymes in the mitochondrial inner membrane (IMM). On the other hand, tBID also targets the mitochondrial outer membrane due to its binding affinity to CL and induces BAX oligomerization which ultimately leads to pore formation and cytochrome c release (19). EPA supplementation not only efficient lengthened the Cardiolipin (CL) chain but also increased CL unsaturation (20).

Omega-3 fatty acids has antiinflammatory and anti-apoptotic effects through the activity and regeneration of endogenous antioxidant mechanisms (21). In pre-eclampsia, the reduced ability of the antioxidant system to overcome lipid peroxidation products (oxidants; free radicals) causes oxidative stress. In addition, the levels of protective antioxidants such as vitamin E decreased, while the amount of lipid peroxidation products in the patient's circulation increased (22).

All vitamin E forms are potent antioxidants, as they scavenge lipid peroxyl radicals by donating hydrogen from the phenolic group on the chromanol ring (23). Vitamin E mainly protects polyunsaturated fatty acids (PUFA) in membrane phospholipids and plasma lipoproteins. Peroxyl radicals react 1000 times faster with 
Yesi Gusti et.al. Omega-3 and vitamin E supplementation effect to rattus norvegicus placental apoptosis marker: pre-eclampsia model.

vitamin E than with PUFAs (24). Vitamin E also effective to intervened apoptosis through decreasing caspase-3 expression, upregulate $\mathrm{Bcl}-2$ expression and alleviate DNA oxidative damage in bone marrow hemopoietic cells at the early stage of steroid-induced femoral head necrosis in rabbit models (25).

Omega-3 fatty acids are sensitive to oxidation, so they are likely to work better with vitamin E than on their own. Previous studies have shown that the combination of omega-3 fatty acids and vitamin $\mathrm{E}$ intake has a strong synergistic effect on glucoserelated markers and fatty acid metabolism which may further work more effectively on biomarkers of oxidative stress and inflammation. Omega-3 fatty acids and vitamin $\mathrm{E}$ co-supplementation for 6 weeks in women with GDM had beneficial effects on plasma TAC, MDA and NO and on the incidence of the newborns hyperbilirubinemia (26).

It is important to consider, Rumbold et al., (2015) at their research said that there are no data showing that vitamin E supplementation or in combination with other supplements is beneficial for preventing stillbirth, neonatal death, premature birth, preeclampsia and PROM. There is no convincing evidence that vitamin $\mathrm{E}$ supplementation in combination with other supplements produces any other significant benefit or harm. In contrast, women who were given vitamin $\mathrm{E}$ supplements alone or in combination with other supplements had an increased risk of premature rupture of membranes (PROM) when compared to women given placebo controls. Further research is needed to elucidate the possible role of vitamin $\mathrm{E}$ in pregnancy (27).

\section{CONCLUSION}

Omega-3 (DHA $120 \mathrm{mg}$, EPA 180 $\mathrm{mg}$ ) and vitamin $\mathrm{E}$ ( $\alpha$-tocopherol 300 iu) supplementation increased BCL-2 level and decreased BAX level on pre-eclampsia rats model.

\section{ACKNOWLEDGMENT}

Special thank for all examiner, Dr. Desmawati, M.Gizi, Dr. Andani Eka Putra, M.Sc. and Dr. Firdawati, M.Kes Ph.D. for their contribution to improve this research. Some of this research funding was provided by Human Resources development and Empowerment Agency, Indonesian Ministry of Health.

\section{Conflict of Interest: None}

\section{Source of Funding: None}

\section{Ethical Approval: Approved}

\section{REFERENCES}

1. POGI. PNPK Diagnosis dan Tatalaksana Preeklampsia. 2016;1-48.

2. Cunningham FG, Roberts JM, Taylor RN. The clinical spectrum of preeclampsia [Internet]. Fourth Edi. Chesley's Hypertensive Disorders in Pregnancy, Fourth Edition. Elsevier Inc.; 2014. 25-36 p. Available from: http://dx.doi.org/10.1016/B978-0-12407866-6.00002-X

3. Marpaung J, Siregar MFG, Sitepu M, Bachtiar A. Black cumin (nigella sativa) effect on expression of TNF- $\alpha$, IL-2, DANsFlt-1in preeclamptic model rats. Int J Curr Pharm Res. 2020;12(4):78-86.

4. McCarthy F, Kenny LC. Hypertension in pregnancy. Obstet Gynaecol Reprod Med [Internet]. 2015;25(8):229-35. Available from:

http://dx.doi.org/10.1016/j.ogrm.2015.05. 004

5. Chen D, Wang W. Human Placental MicroRNAs and Preeclampsia1. Biol Reprod. 2013;88(5):1-11.

6. Tenório MB, Ferreira RC, Moura FA, Bueno NB, De Oliveira ACM, Goulart MOF. Cross-Talk between Oxidative Stress and Inflammation in Preeclampsia. Oxid Med Cell Longev. 2019;2019.

7. Aouache R, Biquard L, Vaiman D, Miralles F. Oxidative stress in preeclampsia and placental diseases. Int $\mathrm{J}$ Mol Sci. 2018;19(5). 
Yesi Gusti et.al. Omega-3 and vitamin E supplementation effect to rattus norvegicus placental apoptosis marker: pre-eclampsia model.

8. Wu F, Tian FJ, Lin Y. Oxidative stress in placenta: Health and diseases. Biomed Res Int. 2015;2015.

9. Evi I, Syafruddin I, Hutahaean S. Article Relationship Between Bcl-2 Expression and Apoptosis Index on Rat (Rattus Norvegicus) Model of Preeclampsia After Administration of Evoo. | Iioabj | [Internet]. 2018;9:1-5. Available from: www.iioab.org

10. Kasture V, Kale A, Randhir K, Sundrani D, Joshi S. Effect of maternal omega-3 fatty acids and vitamin E supplementation on placental apoptotic markers in rat model of early and late onset preeclampsia. Life Sci [Internet]. 2019;239:117038. Available from: https://doi.org/10.1016/j.lfs.2019.117038

11. Arcana N, Sugiritama. Pengaruh Pemberian Minyak Buah Merah (Pandanus conoideus Lam) Terhadap Kadar Vitamin E Plasma Hewan Model Preeklampsia. Medicina (B Aires). 2009;40:27-31.

12. Cardoso PM, Surve S. The Effect of Vitamin E and Vitamin C on the Prevention of Preeclampsia and Newborn Outcome: A Case-Control Study. J Obstet Gynecol India. 2016;66(1):271-8.

13. Jones ML, Mark PJ, Waddell BJ. Maternal dietary omega-3 fatty acids and placental function. Reproduction. 2014;147(5).

14. Wietrak E, Kamiński K, LeszczyńskaGorzelak B, Oleszczuk J. Effect of Docosahexaenoic Acid on Apoptosis and Proliferation in the Placenta: Preliminary Report. Biomed Res Int. 2015;2015.

15. Kovács P, Joó JG, Tamás V, Molnár Z, Burik-Hajas D, Bódis J, et al. The role of apoptosis in the complex pathogenesis of the most common obstetrics and gynaecology diseases. Physiol Int. 2020;107(1):106-19.

16. Varol F, Uzunołlu R, Erbaş $H$, Süt N, Sayin C. VEGFR-1, Bcl-2, and HO-1 ratios in pregnant women with hypertension. Clin Appl Thromb. 2015; 21(3):285-8.

17. Mohammadpour-Gharehbagh A, jahantigh D, Eskandari M, Sadegh MH, Nematollahi $\mathrm{MH}$, Rezaei $\mathrm{M}$, et al. Genetic and epigenetic analysis of the BAX and BCL2 in the placenta of pregnant women complicated by preeclampsia. Apoptosis [Internet]. 2019;24(3-4):301-11. Available from: http://dx.doi.org/10.1007/s10495-0181501-8

18. Amir A, Yanwirasti, Asmarinah, Oenzil F. Alteration expression of bax, Bcl-2 and VDAC1 genes in oligozoospermic and fertile subjects. Pakistan J Biol Sci [Internet]. 2016;19(2):71-6. Available from:

http://dx.doi.org/10.3923/pjbs.2016.71.76

19. Wu CC, Bratton SB. Regulation of the intrinsic apoptosis pathway by reactive oxygen species. Antioxidants Redox Signal. 2013;19(6):546-58.

20. Chang WH, Ting HC, Chen WW, Chan JF, Hsu YHH. Omega-3 and omega-6 fatty acid differentially impact cardiolipin remodeling in activated macrophage. Lipids Health Dis. 2018;17(1):1-11.

21. Hussein S, Abd Elazem MB, Mostafa Ali $H$. The potential anti-inflammatory effect of Omega-3 polyunsaturated fatty acids on experimentally induced ulcerative colitis in rats. Benha Vet Med J. 2019;37(1): 242-9.

22. Subandrate, Faisal ME, Anggraini NW. Peranan Stres Oksidatif pada Preeklampsia. Cermin Dunia Kedokt [Internet]. 2017;44(5):353-5. Available from: http://www.who.

23. Jiang Q. Natural forms of vitamin E: Metabolism, antioxidant, and antiinflammatory activities and their role in disease prevention and therapy. Free Radic Biol Med [Internet]. 2014;72:7690. Available from: http://dx.doi.org/10.1016/j.freeradbiomed. 2014.03.035

24. Leonard SW, Traber MG. Methods for assessment of vitamin $\mathrm{E}$ [Internet]. Laboratory Assessment of Vitamin Status. Elsevier Inc.; 2018. 79-105 p. Available from: https://doi.org/10.1016/B978-0-12813050-6.00004-8

25. Jia YB, Jiang DM, Ren YZ, Liang ZH, Zhao ZQ, Wang YX. Inhibitory effects of Vitamin E on osteocyte apoptosis and DNA oxidative damage in bone marrow 
Yesi Gusti et.al. Omega-3 and vitamin E supplementation effect to rattus norvegicus placental apoptosis marker: pre-eclampsia model.

hemopoietic cells at early stage of steroidinduced femoral head necrosis. Mol Med Rep. 2017;15(4):1585-92.

26. Jamilian M, Hashemi Dizaji S, Bahmani F, Taghizadeh M, Memarzadeh MR, Karamali M, et al. A Randomized Controlled Clinical Trial Investigating the Effects of Omega-3 Fatty Acids and Vitamin E Co-Supplementation on Biomarkers of Oxidative Stress, Inflammation and Pregnancy Outcomes in Gestational Diabetes. Can J Diabetes [Internet]. 2017;41(2):143-9. Available from: http://dx.doi.org/10.1016/j.jcjd.2016.09.00 4

27. Rumbold A, Ota E, Hori H, Miyazaki C, Crowther CA. Vitamin E supplementation in pregnancy. Cochrane Database Syst Rev. 2015;2016(3).

How to cite this article: Gusti Y, Amir A, Revilla G. Omega-3 and vitamin E supplementation effect to rattus norvegicus placental apoptosis marker: pre-eclampsia model. International Journal of Science \& Healthcare Research. 2021; 6(4): 261-268. DOI: https://doi.org/10.52403/ijshr.20211037 